\title{
Cytoreductive surgery with hyperthermic intraperitoneal chemotherapy in management of peritoneal carcinomatosis: Single center experience in Korea
}

Hee Ju Lee', HyungJoo Baik', Yo-Han Park', Sang Hyuk Seo ${ }^{1}$, Kwang Hee Kim¹, Ki Beom Bae', Kwan Hee Hong', Ki Hyang Kim², Jung Mi Byun ${ }^{3}$, Dae Hoon Jeong ${ }^{3}$, Kyung Bok Lee ${ }^{3}$, Min Kyung $\mathrm{Oh}^{4}$, Kwang Rae Cho ${ }^{5}$, Min Sung An ${ }^{1}$

Departments of ${ }^{1}$ Surgery, ${ }^{2}$ Internal Medicine, ${ }^{3}$ Obstetrics and Gynecology, ${ }^{4}$ Clinical Trial Center in Pharmacology, and ${ }^{5}$ Anesthesia and Pain Medicine, Inje University Busan Paik Hospital, Inje University College of Medicine, Busan, Korea

Purpose: Peritoneal carcinomatosis (PC) has been considered a terminal condition and cytoreductive surgery with hyperthermic intraperitoneal chemotherapy (CRS/HIEPC) is regarded as an alternative therapeutic option. This study aimed to evaluate the 30-day clinical outcomes of CRS/HIPEC and the feasibility of the surgery by investigating the morbidity and mortality in Inje University Hospital.

Methods: Data were retrospectively collected from 19 patients with PC who underwent CRS/HIPEC at Inje University Hospital in 2018. We evaluated pre-, intra-operative parameters and postoperative clinical outcomes and early complications.

Results: The mean operating time was 506.95 minutes and the mean blood loss was $837.11 \mathrm{~mL}$. Six cases (31.58\%) had morbidity of grade III or above. A longer operating time ( $\geq 560$ minutes, $P=0.038$ ) and large blood loss $(\geq 700 \mathrm{~mL}, \mathrm{P}=0.060)$ were positively correlated with grade III or worse postoperative complications.

Conclusion: Our early experience with CRS/HIPEC resulted in a 31.58\% morbidity rate of grade III and above, with risk factors being longer operating time and greater intraoperative blood loss. As the surgical team's skills improve, a shorter operating time with less intraoperative blood loss could result in better short-term outcomes of CRS/HIPEC.

Keywords: Peritoneal carcinomatosis, Cytoreductive surgery, Hyperthermic intraperitoneal chemotherapy

\section{INTRODUCTION}

Peritoneal carcinomatosis (PC) can result from either the direct

Received: Jun 27, 2019 Revised: Sep 7, 2019 Accepted: Sep 17, 2019 Correspondence to: Min Sung An

Division of Colorectal Surgery, Department of Surgery, Inje University Busan Paik Hospital, Inje University College of Medicine, 75 Bokji-ro, Busanjin-gu, Busan 47392, Korea

Tel: +82-51-890-6352, Fax: +82-51-898-9427

E-mail: gsams@paik.ac.kr

ORCID: Hee Ju Lee (https://orcid.org/0000-0002-7144-6208), HyungJoo Baik (https://orcid.org/0000-0001-8359-5334), Yo-Han Park (https://orcid.org/00000002-2242-0968), Sang Hyuk Seo (https://orcid.org/0000-0002-7264-1339), Ki Beom Bae (https://orcid.org/0000-0001-7432-9464), Ki Hyang Kim (https://orcid. org/0000-0002-4760-0228), Jung Mi Byun (https://orcid.org/0000-0002-55703606), Dae Hoon Jeong (https://orcid.org/0000-0001-9464-5763), Min Sung An (https://orcid.org/0000-0002-9210-9147)

Copyright (C) 2019 Korean Society of Surgical Oncology

This is an Open Access article distributed under the terms of the Creative Commons Attribution Non-Commercial License (http://creativecommons.org/licenses/by-nc/4.0) which permits unrestricted non-commercial use, distribution, and reproduction in any medium, provided the original work is properly cited. dissemination of gastrointestinal and gynecological cancers or secondary metastasis along the peritoneal surface into the abdominal cavity [1-3]. In patients with a peritoneal metastasis only, cytoreductive surgery with hyperthermic intraperitoneal chemotherapy (CRS/HIPEC) is a potential curative option [4-6]. The basic concept of CRS/HIPEC involves first removing all macroscopic tumors and then delivering hyperthermic anticancer drugs to the microscopic residual tumor cells [7]. Verwaal et al. [8,9] performed a randomized controlled trial with 105 colorectal PC patients, with the median progression-free survival and the median disease-specific survival of 12.6 months and 22.2 months, respectively, in the CRS/HIPEC group, showing better survival than in the systemic chemotherapy only group. Furthermore, there are numerous reports of positive results of CRS/HIPEC in patients with PC [10,11]. Nevertheless, many surgeons are still concerned about the high morbidity and mortality of CRS/HIPEC. A number of reports have shown a $1.1 \%-4.8 \%$ mortality rate and $29.8 \%-43 \%$ grade III/ IV morbidity rate [10,12-14]. Thus, in this study, we would like to evaluate the 30-day clinical outcomes of CRS/HIPEC and the fea- 
sibility of the surgery by investigating the morbidity and mortality in our institution.

\section{METHODS}

Data were retrospectively collected from patients with PC who underwent CRS/HIPEC at Inje University Hospital from January 2018 to December 2018. Individuals older than 80 years, with Eastern Cooperative Oncology Group (ECOG) $\geq 3$, or with extra-abdominal metastasis were excluded. Patients with stage III epithelial ovarian cancer, or peritoneal carcinomatosis of colorectal cancer or pseudomyxoma peritonei without the exclusion criteria were included. The Institutional Review Board of Inje University Hospital, approved this study (IRB No. 19-0025).

\section{Evaluation parameters}

Preoperatively, comorbidities and the American Society of Anesthesiologists (ASA) score were evaluated in all patients. The preoperative peritoneal carcinomatosis index (PCI) score was assessed using abdominopelvic and chest computed tomography (CT), positron emission tomography-CT (PET-CT), and previous diagnostic laparoscopy as available. The intraoperative PCI score (Fig. 1) [15] was assessed using the methods of Jacquet and Sugarbaker [16], which divides the abdominopelvic cavity into 13 regions and each region is graded using the following scale: 0 points, no tumor; 1 point, tumor $<0.5 \mathrm{~cm} ; 2$ points, tumor $0.5-5 \mathrm{~cm} ; 3$ points, tumor
$>5 \mathrm{~cm}$. Completeness of cytoreduction (CC) was assessed using the diameter of the remnant tumor: CC- 0 , complete removal of visible tumor; CC-1, remnant tumor $<0.25 \mathrm{~cm}$; CC-2, residual tumor $0.25-2.5 \mathrm{~cm}$; and CC-3, visible tumor $>2.5 \mathrm{~cm}$.

Postoperative surgical complications were classified using the Clavien-Dindo classification. The postoperative length of stay in the intensive care unit (ICU), length of hospital stays, ICU readmission, postoperative day of first flatus, postoperative day of starting diet, and complication-related readmission after discharge were also evaluated.

\section{CRS/HIPEC procedure}

All patients routinely underwent preoperative bowel preparation. CRS was performed to remove the primary tumor, metastatic lymph nodes, and all intraperitoneal metastases. Parietal peritonectomy and visceral resections were performed using the Sugarbaker technique $[17,18]$. In patients with either an unresectable mass or severe small and large bowel mesenteric seeding, we used a high-voltage monopolar device for cauterization. HIPEC was performed using open and coliseum techniques. First, $3 \mathrm{~L}$ heated perfusion solution (Physionel, 1.5\% dextrose peritoneal dialysis solution) was infused intraperitoneally at $800-1,000 \mathrm{~mL} / \mathrm{min}$ using a Belmont hyperthermic pump. When the intraperitoneal fluid reached $40^{\circ} \mathrm{C}-41^{\circ} \mathrm{C}$, paclitaxel $87.5 \mathrm{mg} / \mathrm{m}^{2}$ was injected initially, followed by $43.75 \mathrm{mg} / \mathrm{m}^{2}$ at 30 and 60 minutes for ovarian cancer; for other cancers, including colorectal cancer, mitomycin-C 17.5

\section{Peritoneal Cancer Index}
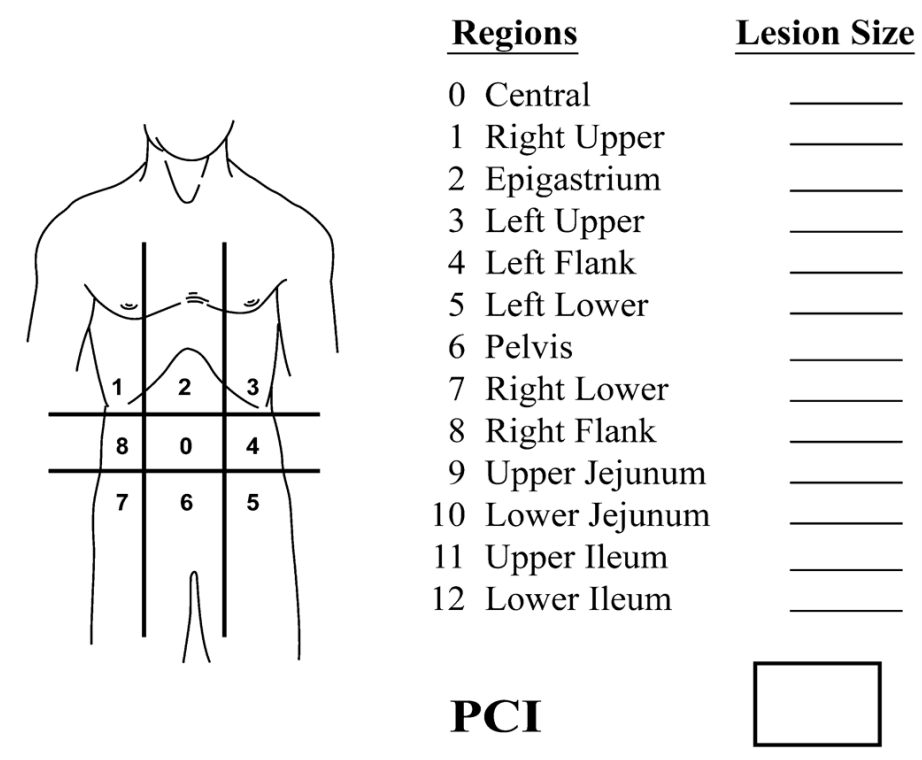

\section{Lesion Size Score}

LS 0 No tumor seen

LS 1 Tumor up to $0.5 \mathrm{~cm}$

LS 2 Tumor up to $5.0 \mathrm{~cm}$

LS 3 Tumor $>5.0 \mathrm{~cm}$ or confluence

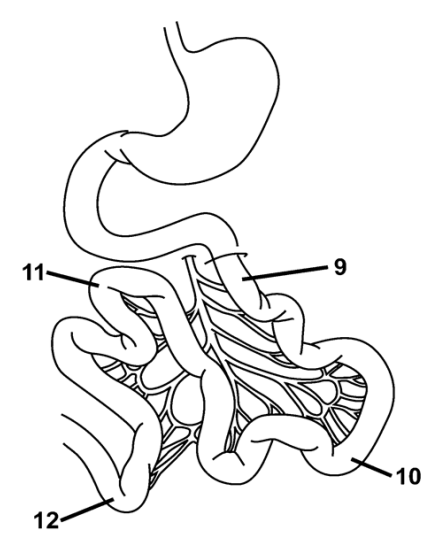

Fig. 1. Peritoneal cancer index (PCI) score. Reprinted from Gilly et al. Eur J Surg Oncol 2006;32:597-601, with permission [15]. 
$\mathrm{mg} / \mathrm{m}^{2}$ was injected initially followed by $8.75 \mathrm{mg} / \mathrm{m}^{2}$ at 30 and 60 minutes. The temperature of the perfusate was maintained at $41^{\circ} \mathrm{C}-42^{\circ} \mathrm{C}$ by monitoring the temperature using pelvic and subphrenic thermometers. Bowel anastomosis, if needed, was performed after HIPEC, and three closed drains were placed in every patient, in the pelvic, right subphrenic, and left subphrenic areas.

\section{Statistical analyses}

We conducted logistic regression to identify risk factors associated with complications. A P-value less than 0.05 was deemed statistically significant. The analyses were performed using SAS 9.4 (SAS Institute, Cary, NC, USA).

\section{RESULTS}

\section{Patient characteristics and perioperative outcomes}

Nineteen patients with colorectal cancer $(\mathrm{n}=8)$, ovarian cancer $(\mathrm{n}=9)$, and pseudomyxoma peritonei $(\mathrm{n}=2)$ underwent CRS/ HIPEC during the study period. Their mean age was 58.63 years and $89.47 \%$ were female. The mean body mass index (BMI) of the patients was $25.77 \pm 3.95 \mathrm{~kg} / \mathrm{m}^{2}$ (range, $21.39-34.72 \mathrm{~kg} / \mathrm{m}^{2}$ ). The ASA score was $<3$ in 17 patients.

The median PCI score was 9 (range, 3-39), and $10.53(2 / 19)$ had a PCI greater than 20. CC- 0 and 1 was attained in $89.47 \%(n=17)$. The mean operating time was 506.95 minutes (range, 340-660 minutes) and the mean blood loss was $837.11 \mathrm{~mL}$ (range, 400$1,510 \mathrm{~mL}$ ). Intraoperative transfusion was performed in $12 \mathrm{pa}-$ tients (63.16\%). Bowel anastomosis was performed in 11 patients $(57.89 \%)$ and enterostomy in eight patients (42.11\%). We used paclitaxel to treat ovarian cancer (47.37\%) and mitomycin-C for colorectal cancer and pseudomyxoma peritonei (52.63\%) (Table 1). The average ICU and hospital stays were 2.26 and 21.42 days, respectively. Patients began sipping water at 4.00 postoperative days and a soft diet at 5.57 postoperative days. Active ambulation was encouraged from 4.11 days postoperatively and the first flatus was at 4.58 postoperative days. Complete removal of the closed drains was done at 12.45 days. Eight patients had packed red blood cell transfusions after surgery. One patient was re-admitted to the ICU with aspiration pneumonia; the patient ultimately died (Table 2).

\section{Postoperative complications according to the Clavien-Dindo classification}

Among grade I postoperative complications, fever was the most common (63.16\%). Common grade II complications were hematological abnormalities, such as anemia, neutropenia, and thrombocytopenia. Regarding grade III complications, six patients underwent interventional therapies for pleural effusion or urine leak-
Table 1. Baseline characteristics and intraoperative outcomes of patients

\begin{tabular}{|c|c|}
\hline Variable & Value $(n=19)$ \\
\hline \multicolumn{2}{|l|}{ Sex } \\
\hline Male & $2(10.53)$ \\
\hline Female & $17(89.47)$ \\
\hline Age (yr) & $58.63 \pm 8.42(40-72)$ \\
\hline BMI $\left(\mathrm{kg} / \mathrm{m}^{2}\right)$ & $25.77 \pm 3.95(21.39-34.72)$ \\
\hline \multicolumn{2}{|l|}{ ASA } \\
\hline 1 & $4(21.05)$ \\
\hline 2 & $13(68.42)$ \\
\hline 3 & $2(10.53)$ \\
\hline \multicolumn{2}{|l|}{ Primary cancer } \\
\hline Colorectal cancer & $8(42.11)$ \\
\hline Ovarian cancer & $9(47.37)$ \\
\hline PMP & $2(10.53)$ \\
\hline \multicolumn{2}{|l|}{ Preoperative PCl } \\
\hline$<10$ & $14(73.68)$ \\
\hline $10-19$ & $3(15.79)$ \\
\hline$\geq 20$ & $2(10.53)$ \\
\hline Preoperative hemoglobin (g/dL) & $11.77 \pm 1.04(9.60-13.30)$ \\
\hline Preoperative WBC (cells/mm³) & $5,758.95 \pm 1,854.54(3,390.00-10,530.00)$ \\
\hline Preoperative albumin (g/dL) & $4.09 \pm 0.35(3.50-4.70)$ \\
\hline Preoperative CRP (mg/dL) & $1.29 \pm 1.78(0.04-7.53)$ \\
\hline \multicolumn{2}{|l|}{ Intraoperative $\mathrm{PCl}$} \\
\hline$<10$ & $10(52.63)$ \\
\hline $10-19$ & $6(31.58)$ \\
\hline$\geq 20$ & $3(15.79)$ \\
\hline \multicolumn{2}{|l|}{ CC score } \\
\hline CC-0 & $13(68.42)$ \\
\hline $\mathrm{CC}-1$ & $4(21.05)$ \\
\hline CC-2 & $2(10.53)$ \\
\hline Operative time (min) & $506.95 \pm 90.16(340.00-660.00)$ \\
\hline Estimated blood loss (mL) & $837.11 \pm 415.09(400.00-1,510.00)$ \\
\hline Intraoperative transfusion & $2.00 \pm 2.69(0.00-10.00)$ \\
\hline Yes & $12(63.16)$ \\
\hline No & $7(36.84)$ \\
\hline \multicolumn{2}{|l|}{ Anastomosis } \\
\hline Yes & $11(57.89)$ \\
\hline No & $8(42.11)$ \\
\hline \multicolumn{2}{|l|}{ Enterostomy } \\
\hline Yes & $8(42.11)$ \\
\hline No & $11(57.89)$ \\
\hline \multicolumn{2}{|l|}{ HIPEC regimen } \\
\hline MTC & $10(52.63)$ \\
\hline Paclitaxel & $9(47.37)$ \\
\hline
\end{tabular}

Values are presented as number (\%) or mean \pm standard deviation (range). $\mathrm{BMI}$, body mass index; ASA, American society of anesthesiologists; PMP, pseudomyxoma peritonei; $\mathrm{PCl}$, peritoneal cancer index; $\mathrm{WBC}$, white blood cell; CRP, C-reactive protein; CC, completeness of cytoreduction; HIPEC, hyperthermic intraperitoneal chemotherapy; MTC, mitomycin-C. 
Table 2. Postoperative clinical outcomes

\begin{tabular}{lc}
\hline Variable & Value $(\mathrm{n}=19)$ \\
\hline Length of ICU stay (day) & $2.26 \pm 1.12(1.00-5.00)$ \\
Length of hospital day (day) & $21.42 \pm 9.20(12.00-52.00)$ \\
Retransfer to ICU & $1(5.26)$ \\
Yes & $18(94.74)$ \\
No & $4.00 \pm 1.41(2.00-7.00)$ \\
Days to 1st sips of water (day) & $5.57 \pm 1.70(3.00-9.00)$ \\
Days to 1st soft diet (day) & $4.58 \pm 1.23(3.00-7.00)$ \\
Days to 1st gas out (day) & $4.11 \pm 1.48(2.00-7.00)$ \\
Days to 1st ambulation (day) & $12.44 \pm 3.86(7.00-22.00)$ \\
Days to removal of JP drain (day) & \\
Postoperative transfusion & \\
Yes & $11(57.11)$ \\
No & \\
\hline
\end{tabular}

Values are presented as mean \pm standard deviation (range).

ICU, intensive care unit; JP, Jackson-Pratt.

age. No patients had to undergo reoperation under general anesthesia. One patient with pleural effusion had a grade V complication; this patient was asphyxiated while undergoing interventional therapy to relieve a pleural effusion (Table 3 ).

Longer operating time ( $\geq 560$ minutes, $\mathrm{P}=0.038$ ) had statistical significance, and large blood loss ( $\geq 700 \mathrm{~mL}, \mathrm{P}=0.060)$ had a tendency of positive correlation with grade III or worse postoperative complications (Table 4).

\section{DISCUSSION}

Historically, PC of gynecological and gastrointestinal malignancies was considered a terminal condition and the only therapy was palliative chemotherapy. In the 1990s, Sugarbaker $[17,19]$ introduced CRS/HIPEC as an alternative therapeutic option in PC. However, many surgical and medical oncologists still doubt the effects of CRS/HIPEC on the oncological prognosis, as the surgical morbidity and mortality remain high; thus, it is still not a popular means of managing PC.

Our postoperative clinical outcomes were similar to those of other CRS/HIPEC studies. Park et al. [20] reported their experience with 66 patients with appendiceal and colorectal cancer with PC. The mean hospital stay was 20.2 days (range, $8-70$ days), mean time to first sipping water was 4.7 days (range, 1-21 days), mean time to first soft diet was 9.5 days (range, $3-4$ days), and mean time to Jackson-Pratt drain removal was 13.4 days (range, 5-43 days). Our results are in line with these values. Another study reported comparable data [21].

A systemic review of CRS/HIPEC in PC of colorectal origin reported a perioperative morbidity rate of $14.8 \%-57 \%$ and mortality
Table 3. Postoperative complications

\begin{tabular}{lc}
\hline Grade & No. of patients (\%) \\
\hline Grade I & \\
Fever & $12(63.16)$ \\
Constipation & $3(15.79)$ \\
Diarrhea & $2(10.53)$ \\
Ileus & $1(5.26)$ \\
Confusion & $1(5.26)$ \\
Nausea \&t vomiting & $1(5.26)$ \\
Voiding difficulty & $1(5.26)$ \\
Wound pain & $1(5.26)$ \\
Grade II & \\
Transfusion & $8(42.11)$ \\
Thrombocytopenia & $4(21.05)$ \\
Neutropenia & $3(15.79)$ \\
Tachycardia & $1(5.26)$ \\
Back pain & $1(5.26)$ \\
Grade III & \\
Pleural effusion & $5(26.32)$ \\
Urine leakage & $1(5.26)$ \\
Grade V & $1(5.26)$ \\
Death & \\
\hline
\end{tabular}

rate of $0 \%-12.0 \%$ [22]. Another systemic review of CRS/HIPEC for malignancy of varying origins reported $0 \%-52 \%$ postoperative morbidity, the most common complications being anastomotic leakage, venous thromboembolism, and hematologic toxicity [23]. In this study, we categorized the postoperative complications using the Clavien-Dindo classification. The most common grade I complication was fever. Patients mostly had fever within three postoperative days; this is probably due to atelectasis from the long operation or postoperative ventilator care. Among grade II complications, the most common were hematological abnormalities such as anemia, neutropenia, or thrombocytopenia. This was common at 5 to 7 postoperative days, and was corrected by transfusion or hematopoietic agents. Six cases (31.58\%) had morbidity of grade III or above. Although our study appeared to have a higher overall morbidity rate than other studies, this is probably because we considered various complications that the other studies did not include. Notably, our grade III and above morbidity rate was similar to that of other studies [10,12-14]. Fortunately, there were no major complications such as bleeding or anastomotic leakage requiring reoperation in our study, and only five patients needed interventional therapy for pleural effusion.

Examining 76 patients with CRS/HIPEC, Arakelian et al. [24] noted that the PCI and ASA scores predicted pleural effusion. Our five patients with pleural effusions all had very severe diaphragmatic PC needing extensive diaphragmatic peritonectomy. Therefore, patients undergoing diaphragmatic peritonectomy require 
Table 4. Risk factors associated with grade III or worse postoperative complications with CRS+HIPEC

\begin{tabular}{|c|c|c|c|c|}
\hline Factor & Classification & $\mathrm{OR}$ & $95 \% \mathrm{Cl}$ & P-value \\
\hline \multirow[t]{2}{*}{ Sex } & Male & Reference & & \\
\hline & Female & 3.57 & $(0.07-41.70)$ & 0.971 \\
\hline \multirow[t]{2}{*}{ Age (yr) } & $<55$ & 6.67 & $(0.79-56.22)$ & 0.081 \\
\hline & $\geq 55$ & Reference & & \\
\hline \multirow[t]{2}{*}{ BMI $\left(\mathrm{kg} / \mathrm{m}^{2}\right)$} & $<24$ & 7.50 & $(0.92-61.05)$ & 0.060 \\
\hline & $\geq 24$ & Reference & & \\
\hline \multirow[t]{2}{*}{ ASA } & $1 \& 2$ & Reference & & \\
\hline & 3 & 1.83 & $(0.10-34.85)$ & 0.687 \\
\hline \multirow[t]{2}{*}{ Preoperative hemoglobin $(\mathrm{g} / \mathrm{dL})$} & $<11.2$ & Reference & & \\
\hline & $\geq 11.2$ & 4.29 & $(0.39-47.62)$ & 0.236 \\
\hline \multirow[t]{2}{*}{ Preoperative WBC (cells/mm³) } & $<6,980$ & 19.44 & (0.16-84.93) & 0.961 \\
\hline & $\geq 6,980$ & Reference & & \\
\hline \multirow[t]{2}{*}{ Preoperative albumin (g/dL) } & $\geq 3.5$ & Reference & & \\
\hline & $<3.5$ & 0.56 & $(0.08-4.14)$ & 0.570 \\
\hline \multirow{2}{*}{ Preoperative CRP (mg/dL) } & $\leq 1$ & Reference & & \\
\hline & $>1$ & 5.00 & $(0.66-38.15)$ & 0.121 \\
\hline \multirow[t]{3}{*}{ GPS } & 0 & - & & \\
\hline & 1 & 1.50 & $(0.22-10.22)$ & 0.679 \\
\hline & 2 & - & & \\
\hline \multirow[t]{2}{*}{ HIPEC regimen } & MTC & Reference & & \\
\hline & Paclitaxel & 0.54 & $(0.08-3.53)$ & 0.517 \\
\hline \multirow[t]{2}{*}{$\mathrm{PCl}$ index } & $<7$ & Reference & & \\
\hline & $\geq 7$ & 6.00 & $(0.54-66.15)$ & 0.144 \\
\hline \multirow[t]{2}{*}{ CC score } & $0 \& 1$ & Reference & & \\
\hline & 2 & 3.57 & $(0.07-41.70)$ & 0.971 \\
\hline \multirow[t]{2}{*}{ Anastomosis } & Absent & Reference & & \\
\hline & Present & 0.40 & $(0.06-2.93)$ & 0.367 \\
\hline \multirow[t]{2}{*}{ Enterostomy } & Absent & Reference & & \\
\hline & Present & 0.95 & $(0.14-6.28)$ & 0.960 \\
\hline \multirow[t]{2}{*}{ Operative time (min) } & $<560$ & Reference & & \\
\hline & $\geq 560$ & 14.67 & $(1.16-185.23)$ & 0.038 \\
\hline \multirow[t]{2}{*}{ Blood loss (mL) } & $<700$ & Reference & & \\
\hline & $\geq 700$ & 7.50 & $(0.92-61.05)$ & 0.060 \\
\hline \multirow[t]{2}{*}{ Intraoperative transfusion } & $>2$ & 3.75 & $(0.45-31.62)$ & 0.224 \\
\hline & $\leq 2$ & Reference & & \\
\hline
\end{tabular}

CRS, cytoreductive surgery; HIPEC, hyperthermic intraperitoneal chemotherapy; OR, odds ratio; $\mathrm{Cl}$, confidence interval; BMI, body mass index; ASA, American society of anesthesiologists; WBC, white blood cells; CRP, C-reactive protein; GPS, Glasgow Prognostic Score; PCl, peritoneal cancer index; CC, completeness of cytoreduction.

meticulous postoperative pulmonary monitoring and care.

Many studies have reported that a longer operating time is a risk factor for postoperative complications (infectious complications, sepsis, and pulmonary complications) [25-29]. Daley et al. [25] noted that in cases with long operating times, there were increases in infectious complications, deep vein thrombosis, and wound disruption; for every 1,000 cases, there were 116 complications per operating room hour. We also found that a longer operating time was a risk factor for grade III complications (odds ratio, 14.67; $\mathrm{P}=0.038$ ). Many factors affect the operating time, such as the pa- tient's BMI, number of organs resected, prior surgery, and the surgical team's experience. Another factor with a tendency to contribute to an increase in complications was a large intraoperative blood loss (odds ratio, 7.50; $\mathrm{P}=0.060$ ). In a study of 1554 colorectal cancer patients, Okamura et al. [30] found that intraoperative blood loss has a detrimental effect on morbidity; blood loss $>200$ $\mathrm{mL}(46 \%)$ had a higher morbidity rate than blood loss $<200 \mathrm{~mL}$ $(30 \%)$.

This study was limited by its small sample size and retrospective nature. However, it has value in reporting our early experience 
with CRS/HIPEC in a single center in Korea, with a frank description of the short-term clinical outcomes.

In conclusion, our early experience with CRS/HIPEC resulted in a $31.58 \%$ morbidity rate of grade III and above, with risk factors being longer operating time and greater intraoperative blood loss. As the surgical team's skills improve, a shorter operating time with less intraoperative blood loss could result in better short-term outcomes of CRS/HIPEC.

\section{CONFLICT OF INTEREST}

No potential conflict of interest relevant to this article was reported.

\section{ACKNOWLEDGMENTS}

We would like to thank Nr. Mi Kyung Jung, Kum Ryun Chun, Ho Jung Jo, and Dan Bi Heo for participating in this study.

\section{REFERENCES}

1. Lambert LA. Looking up: recent advances in understanding and treating peritoneal carcinomatosis. CA Cancer J Clin 2015;65:28498.

2. Yan TD, Black D, Savady R, Sugarbaker PH. Systematic review on the efficacy of cytoreductive surgery combined with perioperative intraperitoneal chemotherapy for peritoneal carcinomatosis from colorectal carcinoma. J Clin Oncol 2006;24:4011-9.

3. Yan TD, Black D, Savady R, Sugarbaker PH. A systematic review on the efficacy of cytoreductive surgery and perioperative intraperitoneal chemotherapy for pseudomyxoma peritonei. Ann Surg Oncol 2007;14:484-92.

4. Esquivel J, Elias D, Baratti D, Kusamura S, Deraco M. Consensus statement on the loco regional treatment of colorectal cancer with peritoneal dissemination. J Surg Oncol 2008;98:263-7.

5. Spiliotis J, Halkia E, Lianos E, Kalantzi N, Grivas A, Efstathiou E, et al. Cytoreductive surgery and HIPEC in recurrent epithelial ovarian cancer: a prospective randomized phase III study. Ann Surg Oncol 2015;22:1570-5.

6. Elit L, Oliver TK, Covens A, Kwon J, Fung MF, Hirte HW, et al. Intraperitoneal chemotherapy in the first-line treatment of women with stage III epithelial ovarian cancer: a systematic review with metaanalyses. Cancer 2007;109:692-702.

7. Sugarbaker PH, Van der Speeten K, Stuart OA. Pharmacologic rationale for treatments of peritoneal surface malignancy from colorectal cancer. World J Gastrointest Oncol 2010;2:19-30.

8. Verwaal VJ, van Ruth S, de Bree E, van Sloothen GW, van Tinteren $\mathrm{H}$, Boot $\mathrm{H}$, et al. Randomized trial of cytoreduction and hyper- thermic intraperitoneal chemotherapy versus systemic chemotherapy and palliative surgery in patients with peritoneal carcinomatosis of colorectal cancer. J Clin Oncol 2003;21:3737-43.

9. Verwaal VJ, Bruin S, Boot H, van Slooten G, van Tinteren H. 8-year follow-up of randomized trial: cytoreduction and hyperthermic intraperitoneal chemotherapy versus systemic chemotherapy in patients with peritoneal carcinomatosis of colorectal cancer. Ann Surg Oncol 2008;15:2426-32.

10. Elias D, Gilly F, Boutitie F, Quenet F, Bereder JM, Mansvelt B, et al. Peritoneal colorectal carcinomatosis treated with surgery and perioperative intraperitoneal chemotherapy: retrospective analysis of 523 patients from a multicentric French study. J Clin Oncol 2010;28:63-8.

11. van Driel WJ, Koole SN, Sikorska K, Schagen van Leeuwen JH, Schreuder HWR, Hermans RHM, et al. Hyperthermic intraperitoneal chemotherapy in ovarian cancer. N Engl J Med 2018;378: 230-40.

12. Glehen O, Gilly FN, Boutitie F, Bereder JM, Quenet F, Sideris L, et al. Toward curative treatment of peritoneal carcinomatosis from nonovarian origin by cytoreductive surgery combined with perioperative intraperitoneal chemotherapy: a multi-institutional study of 1,290 patients. Cancer 2010;116:5608-18.

13. van Leeuwen BL, Graf W, Pahlman L, Mahteme H. Swedish experience with peritonectomy and HIPEC. HIPEC in peritoneal carcinomatosis. Ann Surg Oncol 2008;15:745-53.

14. Chua TC, Saxena A, Schellekens JF, Liauw W, Yan TD, Fransi S, et al. Morbidity and mortality outcomes of cytoreductive surgery and perioperative intraperitoneal chemotherapy at a single tertiary institution: towards a new perspective of this treatment. Ann Surg 2010;251:101-6.

15. Gilly FN, Cotte E, Brigand C, Monneuse O, Beaujard AC, Freyer G, et al. Quantitative prognostic indices in peritoneal carcinomatosis. Eur J Surg Oncol 2006;32:597-601.

16. Jacquet $P$, Sugarbaker PH. Clinical research methodologies in diagnosis and staging of patients with peritoneal carcinomatosis. Cancer Treat Res 1996;82:359-74.

17. Sugarbaker PH. Peritonectomy procedures. Ann Surg 1995;221:2942.

18. Sugarbaker PH. Management of peritoneal metastases: basic concepts. J BUON 2015;20 Suppl 1:S2-11.

19. Sugarbaker PH. Surgical management of peritoneal carcinosis: diagnosis, prevention and treatment. Langenbecks Arch Chir 1988;373:189-96.

20. Park EJ, Baik SH, Hur H, Min BS, Kang J, Han YD, et al. Cytoreductive surgery with hyperthermic intraperitoneal chemotherapy for appendiceal and colorectal cancer with peritoneal carcinomatosis: clinical outcomes at 2 tertiary referral centers in Korea. Medicine 
(Baltimore) 2017;96:e6632.

21. Polanco PM, Ding Y, Knox JM, Ramalingam L, Jones H, Hogg ME, et al. Institutional learning curve of cytoreductive surgery and hyperthermic intraperitoneal chemoperfusion for peritoneal malignancies. Ann Surg Oncol 2015;22:1673-9.

22. Cao C, Yan TD, Black D, Morris DL. A systematic review and meta-analysis of cytoreductive surgery with perioperative intraperitoneal chemotherapy for peritoneal carcinomatosis of colorectal origin. Ann Surg Oncol 2009;16:2152-65.

23. Chua TC, Yan TD, Saxena A, Morris DL. Should the treatment of peritoneal carcinomatosis by cytoreductive surgery and hyperthermic intraperitoneal chemotherapy still be regarded as a highly morbid procedure?: a systematic review of morbidity and mortality. Ann Surg 2009;249:900-7.

24. Arakelian E, Torkzad MR, Bergman A, Rubertsson S, Mahteme H. Pulmonary influences on early post-operative recovery in patients after cytoreductive surgery and hyperthermic intraperitoneal chemotherapy treatment: a retrospective study. World J Surg Oncol 2012;10:258.

25. Daley BJ, Cecil W, Clarke PC, Cofer JB, Guillamondegui OD. How slow is too slow? Correlation of operative time to complications: an analysis from the Tennessee Surgical Quality Collaborative. J Am Coll Surg 2015;220:550-8.

26. Kirchhoff P, Clavien PA, Hahnloser D. Complications in colorectal surgery: risk factors and preventive strategies. Patient Saf Surg 2010;4:5.

27. Pessaux P, Msika S, Atalla D, Hay JM, Flamant Y; French Association for Surgical Research. Risk factors for postoperative infectious complications in noncolorectal abdominal surgery: a multivariate analysis based on a prospective multicenter study of 4718 patients. Arch Surg 2003;138:314-24.

28. Canet J, Gallart L, Gomar C, Paluzie G, Valles J, Castillo J, et al. Prediction of postoperative pulmonary complications in a population-based surgical cohort. Anesthesiology 2010;113:1338-50.

29. Procter LD, Davenport DL, Bernard AC, Zwischenberger JB. General surgical operative duration is associated with increased risk-adjusted infectious complication rates and length of hospital stay. J Am Coll Surg 2010;210:60-5.

30. Okamura R, Hida K, Hasegawa S, Sakai Y, Hamada M, Yasui M, et al. Impact of intraoperative blood loss on morbidity and survival after radical surgery for colorectal cancer patients aged 80 years or older. Int J Colorectal Dis 2016;31:327-34. 